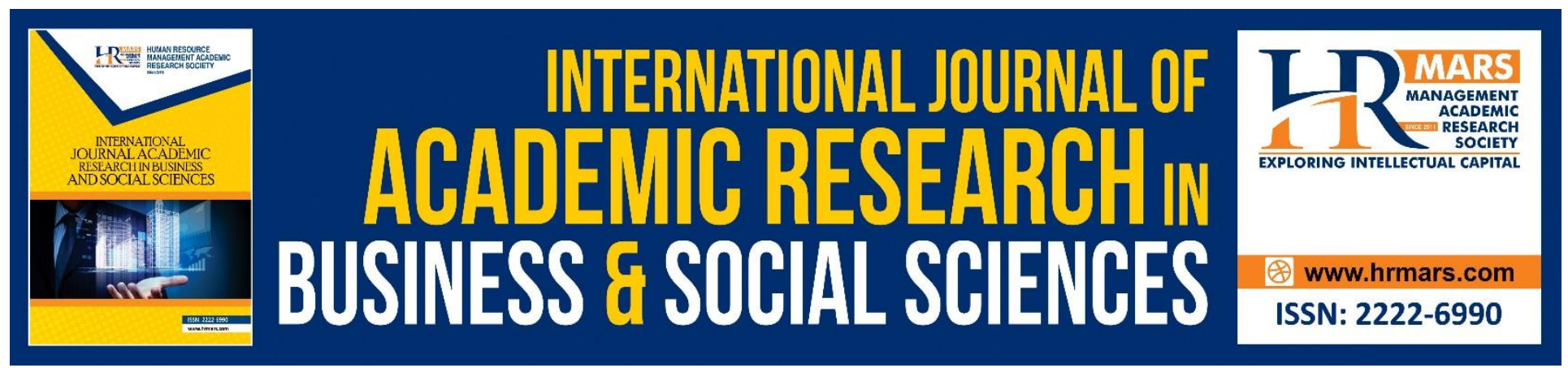

\title{
The Social Impact of Video Games' Cinematics: Changing Attention levels Resulting in Rhythmic Transitions
}

Muhammad Fadhil Wong Abdullah, Muhammad Zaffwan Idris, Nor Shahida Mohd Jamail

To Link this Article: http://dx.doi.org/10.6007/IJARBSS/v10-i8/7666

DOI:10.6007/IJARBSS/v10-i8/7666

Received: 15 May 2020, Revised: 18 June 2020, Accepted: 25 July 2020

Published Online: 30 August 2020

In-Text Citation: (Abdullah, Idris, \& Jamail, 2020)

To Cite this Article: Abdullah, M. F. W., Idris, M. Z., \& Jamail, N. S. M. (2020). The Social Impact of Video Games' Cinematics: Changing Attention levels Resulting in Rhythmic Transitions. International Journal of Academic Research in Business and Social Sciences. 10(8), 955-961.

Copyright: @ 2020 The Author(s)

Published by Human Resource Management Academic Research Society (www.hrmars.com)

This article is published under the Creative Commons Attribution (CC BY 4.0) license. Anyone may reproduce, distribute, translate and create derivative works of this article (for both commercial and non-commercial purposes), subject to full attribution to the original publication and authors. The full terms of this license may be seen

at: http://creativecommons.org/licences/by/4.0/legalcode

\section{Vol. 10, No. 8, 2020, Pg. 955 - 961}

Full Terms \& Conditions of access and use can be found at http://hrmars.com/index.php/pages/detail/publication-ethics 


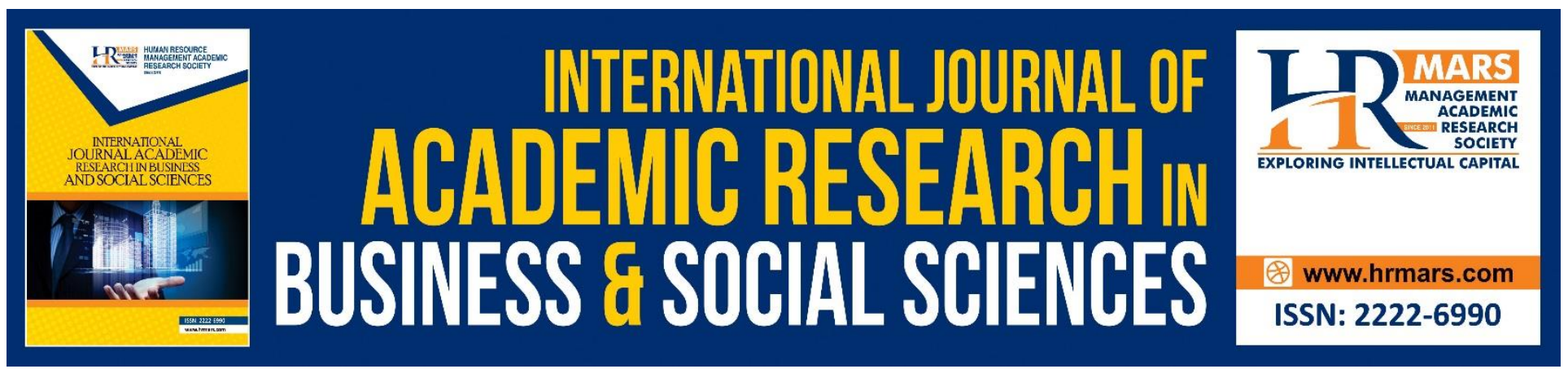

\section{The Social Impact of Video Games' Cinematics: Changing Attention levels Resulting in Rhythmic Transitions}

\section{Muhammad Fadhil Wong Abdullah, Muhammad Zaffwan Idris, Nor Shahida Mohd Jamail}

Faculty of Art, Computing and Creative Industry, Universiti Pendidikan Sultan Idris, Malaysia.

Email: fadhil.wong@fskik.upsi.edu.my

\section{Abstract}

This research investigates the social impact of video games' cinematics on video game players. The researcher will be looking at how these gamers are interacting with the computer generated images (CGI) and life action cut-scene videos shown to them during their weekly video game playing sessions thus changing their attention levels resulting in rhythmic transitions.

This paper investigates the actions of gamer during the transitions from game play into cut-scenes and cut-scenes back to game play. Cut-scenes usually appear as introductions, but are also shown after certain missions or once objectives are completed. Drawing on Mediated Discourse Analysis and Multimodal Interaction Analysis, the exact lower-level action - pressing a button and higher-level action - playing a game provides important insights throughout the entire video game playing session obtained through video ethnography method. Video data including on-screen game play, participant gaming and interviews were collected over a period of twelve weeks. The exact lower-level and higher-level actions are investigated and illustrating through short video clips and with multimodal transcripts clearly demonstrating how the attention of a gamer shifts during these transition periods. Findings provide important insights to games' developers to have a better understanding and able to utilize transition period during cut-scenes in order to create a better game playing experiences to the gamers.

Keywords: Cut-scenes, Mediated Discourse Analysis, Multimodal Interaction Analysis, Video Games, Gamer Interaction

\section{Introduction}

In the past few decades, we have witnessed an increase in research of computer and video games. The video games' industries generated a total of $\$ 99.6$ billion in revenues worldwide in 2016. However the global games market value rises to $\$ 134.9$ billion in 2018 and it was $\$ 152.1$ billion in 2019 ! Video games have been a subject of serious research in the last decade even though video 
games have been a part of home entertainment for more than thirty years (Chen, 2013). A growing number of research studies have been conducted looking at video game players' experiences in video games using various frameworks and methodologies with the increasing popularity of video games (Lemay \& Maheux-Lessard, 2012). The commercial success and huge revenue in the current video games industry, drives more academic interest in games and game studies (Myers, 2006). Console and hand-held games are currently the most popular types of electronic play (Salonius-Pasternak \& Gelfond, 2005). This study derived from two main models; Mediated Discourse Analysis (MDA) and Multimodal Interaction Analysis (MIA), which focusing on the actions performed by the gamers throughout their game playing sessions. These models provide an important insight to game developers allowing them to enhance the gamers' experience. Based from these two models, this study will further explore on the actions that the gamers performed during the in-game cut-scenes (Norris, 2011, 2004; Scollon, 2005).

This paper looks at action of a video gamer called Naz (not real name) during the transition between video game playing and in-game cut-scenes while he was playing a real time strategy game on the Microsoft Xbox 360 console. According to Lindley (2005) cut-scenes or cinematics are sequences of non-interactive animation and pre-rendered video. They are intended as supplementary to enhance game play and simulate the movie theatre experience. Videos obtained in this study of participant gaming and on-screen game plays provide insights into the mediated actions during transitions. Subsequently, it gives us insight into various lower-level and higher-levels actions undertaken by one social actor, Naz. His multiple higher-level actions are all interlinked and synchronized thus creating a rhythmic pattern through switching from playing a game to using a laptop and back playing his game again. Multimodal Interaction Analysis (Norris, 2011), building upon Mediated Discourse Analysis (MDA) (Scollon, 2005), allows us to examine Naz's attention-shifting during transitions into cut-scenes as action is treated as a unit of analysis in both MDA and MIA. It appears that video gamers treat the in-game cut-scenes as a short break during their video game playing session. Most of them relax their body by leaning back; and some of them shift their attention to their cell phone and/or laptop during these cut-scenes transition period. Then, they refocus again for the next mission at a point in time before the end of each cut-scene.

\section{Study Of Rhythm}

Rhythm as an internally generated phenomenon which occurs at all time scales. He claims it is impossible for us to walk without a rhythm; it is easier to perform a physical activity rhythmically (Scollon, 1998). The examination on how walking is surrounded by notions of style that reproduce rhythms. Our own particular mode of walking rhythms changes according to many factors such as location (in a square or railway stations), time (shop opening hours, lunchtime or season) and weather which all have an effect on our rhythm of walking.

Not only, performing a simple physical activity such as walking can be seeing as something impossible to achieve without a rhythm, Scollon (1998) also looked at how a child at the age of three to four years old is capable of tapping along with a song. He was interested not because of the regularity of the tapping but due to the synchrony where the child recognizes the regularity of the pulse. This rhythm generated phenomenon which occurs at all time scales does happens to both adult and children. 
INTERNATIONAL JOURNAL OF ACADEMIC RESEARCH IN BUSINESS AND SOCIAL SCIENCES Vol. 10, No. 8, 2020, E-ISSN: 2222-6990 @ 2020 HRMARS

During his home restoration project in Alaska, the rhythmic integration of lower-level and higher-level action sequences and identified six rhythmic pace-makers. The further explained how all six cycles were interconnected and how they relate together in a simple situation such as during the floor-nailing session. These integration cycles as being similar to integrated gears such as the gearbox in a vehicle (Scollon, 2005). That rhythm of a spoken language performed by one social actor could be well responded to by using hand-arm movements by another social actor. Thus, a spoken utterance is rhythmically responded through a set of gestures (Norris, 2009).

\section{Multimodal Interaction Analysis (Mia)}

A social actor may be performing several different higher-level actions simultaneously which will always have different levels of awareness and attention. According to Norris (2004), there is a continuum between foreground, mid-ground and background (Figure 1). The action performed in the foreground carries a higher modal density thus telling us the importance that the social actor performing the action places upon it. Whereas, mid-grounded and backgrounded higher-level actions demonstrate decreased levels of attention and awareness as the modal density is reduced (Figure 1).

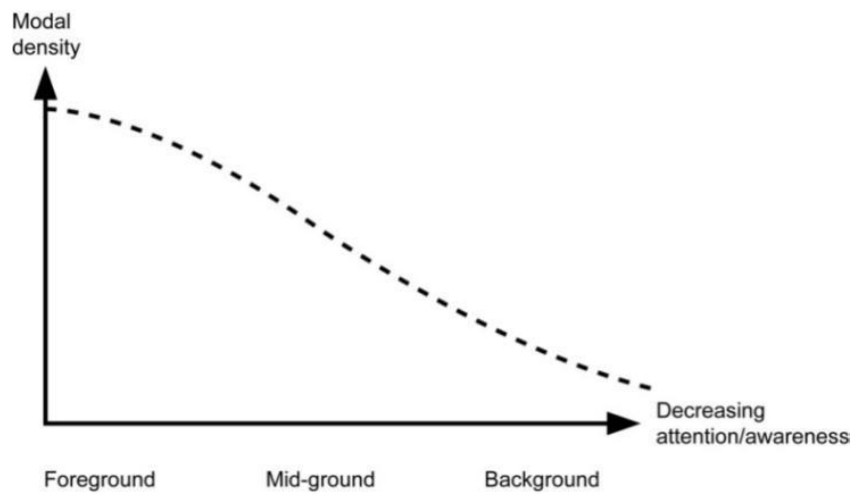

Figure 1: Modal density foreground-background continuum (Norris, 2004, p.99)

The social actor is aware and does pay attention to their other higher level actions such as those located on their mid-ground and background even though they are engaging in only one focused interaction.

\section{Multimodal Interaction Analysis: Semantic/Pragmatic Means}

A semantic/pragmatic means is a means that helps to delineate a certain higher-level action (Norris, 2004): “

i. A means functions semantically by marking the end of a foregrounded higher-level action (or the beginning of a new higher-level action), facilitating the organization of higher-level actions in the performer's own mind

ii. A means functions pragmatically by communicating the upcoming occurrence of a shift in foregrounded higher-level action to the other participants."

(Norris, 2004, p.117)

A means is a way of doing something such as a simple up-down hand gesture performed by Naz during his video gaming session. Usually a person will show a semantic/pragmantic means before the focuses change; just before shifting their focus, that is where semantic/pragmatic means occur. 
INTERNATIONAL JOURNAL OF ACADEMIC RESEARCH IN BUSINESS AND SOCIAL SCIENCES Vol. 10, No. 8, 2020, E-ISSN: 2222-6990 @ 2020 HRMARS

Naz's hand gesture itself is non-related to his current higher-level action and his upcoming higherlevel action. It is not link to the action that he was performing at that time and the up-down hand gesture alone is a pronounced lower-level action.

\section{Analysis: Changing Attention Levels Resulting In Rhythmic Transitions}

The following figures (Figure 2) illustrate Naz during one gaming session of Command and Conquer Tiberium Wars. Here, Naz is seen engaging in multiple higher-level actions simultaneously. The video game playing session took place in his spare room which he had dedicated to video gaming. As can be seen in Figure 2, Naz was sitting on the floor throughout this entire gaming session; this is his typical place as he always sits on the floor when he plays his video games. Occasionally he moved his back against the wall behind him. His LCD game play screen was positioned in front of Naz; and his sitting position allows him to have full front view of the LCD when he is playing the game. His laptop and the mouse are both located in front of him but slightly to his right side. The laptop and mouse are positioned in a way that can be seen as part of his gaming room setup. Both items are close to him and he can easily have access to them from his sitting position. Whenever he switches over to using his laptop, Naz always leaves the controller between the laptop and him to allow for easy and quick reach.

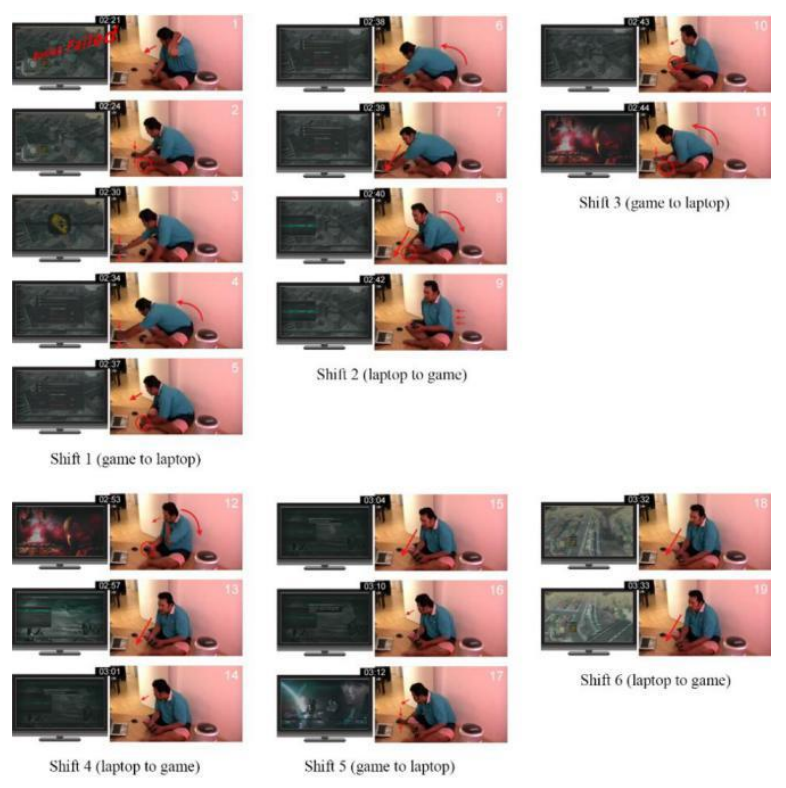

Figure 2: Naz during a video game playing session

This switch of attention levels is accomplished in a much synchronized manner (Figure 2). While he is using the laptop is a separate higher-level action, the laptop itself can be seen as a wellintegrated part of his gaming session. Each higher-level action has different levels of attention and awareness; the final transcripts illustrate how Naz switches back and forth from playing his game to using his laptop. His multiple higher-level actions are all interlinked and synchronized thus creating a rhythmic pattern through switching from playing a game to using a laptop and back playing a game again (Norris, 2004). 
INTERNATIONAL JOURNAL OF ACADEMIC RESEARCH IN BUSINESS AND SOCIAL SCIENCES Vol. 10, No. 8, 2020, E-ISSN: 2222-6990 @ 2020 HRMARS

The switching over; ( $A$ to $B$ ) or ( $B$ to $A$ ) that took place during each transition period provides us a perfectly linked and synchronized rhythm of his game play in Figure 3.

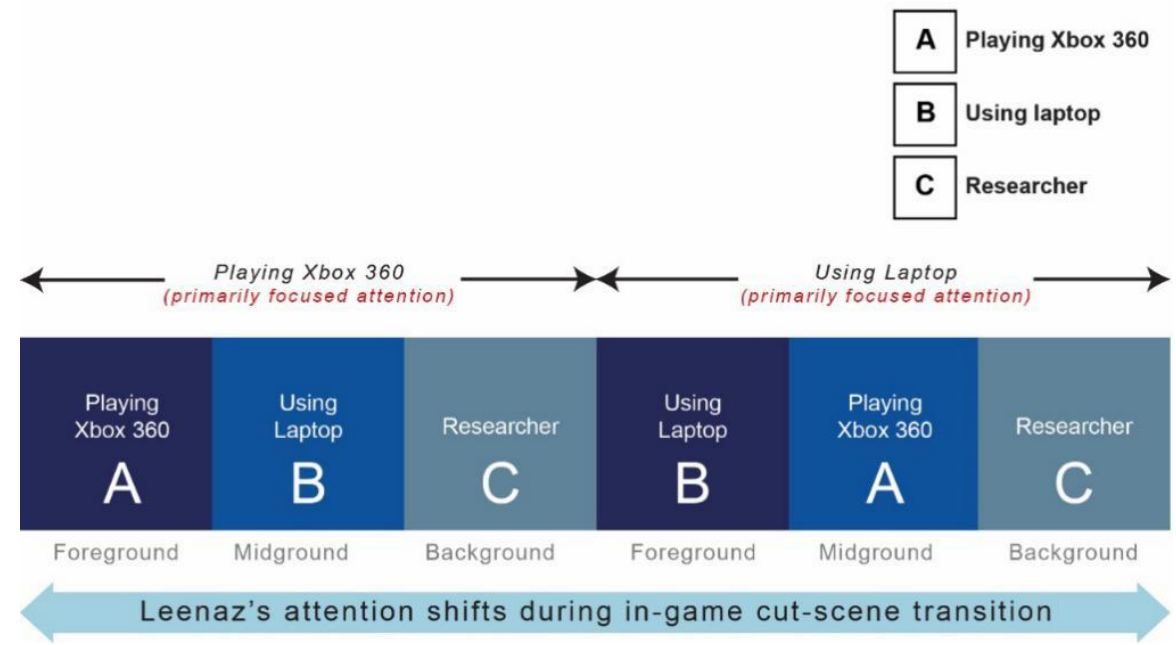

Figure 3: Rhythmic transition of $\mathrm{Naz}$

\section{Conclusion}

The only differences between these higher-level actions are where they are located in the three different horizontal levels of attention and awareness; foreground, mid-ground and background. However, there was always a semantic/pragmatic means we could locate from one of his lower-levels action. Although his higher-level action switched from playing a game to using a laptop or the other way which seems to be two different forms of mediated actions but both actions were still within his game play session.

Using the laptop can be seen as unrelated to his video gaming session, but in fact both playing the game and using laptop were rhythmically positioned during this course of game play session. However, the research study has found out none of the in-game cut-scenes resulted any form of social impact on the video game player. Not only that, Naz can be clearly seen switching his attention levels and engaging into another higher-level action during each of the in-game cut-scene moment. Further research is needed to identify the potential and improvements of video gaming have to offer during these cut-scenes transitions moment.

Although video games can, and often do consist of both immersive interactivity and in-game cinematic cut-scenes, these are two distinct modes of visualising the game-environment that cannot be synthesized.

\section{Acknowledgement}

This paper is based on the research project entitled, The Social Impact of Video Games Cinematics: Case Studies of Professional Malaysia Video Game Players. The authors would like to 
INTERNATIONAL JOURNAL OF ACADEMIC RESEARCH IN BUSINESS AND SOCIAL SCIENCES

Vol. 10, No. 8, 2020, E-ISSN: 2222-6990 @ 2020 HRMARS

extend their gratitude to Universiti Pendidikan Sultan Idris for the University Research Grants (code: 2017-0023-106-01) that helped fund the research.

\section{References}

Chen, C-Y. (2013). Is the Video Game a Cultural Vehicle? Games and Culture, 8(6), 408-427, doi: $10.1177 / 1555412013493349$

Juul, J. (2001) Games telling stories? A brief note on games and narratives, The International Journal of Computer Game Research: Volume 1, Issue 1, July 2001

Lindley, C. A. (2005). Story and Narrative Structures in Computer Games: Developing Interactive Narrative Content. Bushoff: Brunhild.

Lemay, P., \& Maheux-Lessard, M. (2012). Investigating Experiences and Attitudes toward Videogames Using a Semantic Differential Methodology. In Bernhaupt, R. (Ed.) Evaluating User Experience in GamesConcepts and Methods. New York, USA: Springer London Dordrecht Heidelberg.

Lankshear, C., Knobel, M., \& Peters, M. (2009) Perceiving Play: The Art and Study of Computer Games. New York: Peter Lang Publishing.

Myers, D. (2006). Signs, symbols, games and play. Games and Culture, 1, 47-51.

Newman, J. (2004) Video games, New York: Routledge.

Norris, S. (2011). Identity in (inter)action: Introducing multimodal (inter)action analysis. Gottingen Germany: DeGruyter Mouton.

Norris, S. (2009). Modal density and modal configurations: Multimodal actions. In Jewit, C. (Ed.) Routledge Handbook for Multimodal Discourse Analysis. London: Routledge.

Norris, S. (2004). Analyzing multimodal interaction: A methodological framework. New York: Routledge.

Salonius-Pasternak, D., \& Gelfond, H. S. (2005). The next level of research on electronic play: Potential benefits and contextual influences for children and adolescents. An interdisciplinary journal on humans in ICT environments, Volume 1, 1, 5-22.

Scollon, R. (2005). The Rhythmic Integration of Action and Discourse: Work, the Body and the Earth. In Norris, S. \& Jones, R. (Eds.), Discourse in Action: Introducing mediated discourse analysis. Oxon: Routledge.

Scollon, R. (1998). Mediated Discourse As Social Interaction: A Study of News Discourse. New York: Longman.

Sethares, W. (2007). Rhythm and transforms, perceptions and mathematics. Mathematics and computation in music. Springer Berlin Heidelberg. doi: 10.1007/978-3-642-04579-0_1. 